\title{
MODEL PEMBELAJARAN STAD MELALUI MEDIA KOTAK KARTU MISTERIUS (KOKAMI): PENERAPAN TERHADAP HASIL BELAJAR FISIKA SMP MATERI USAHA DAN PESAWAT SEDERHANA
}

\author{
Desti Prastikawati $^{1 *}$, Siti Anisatur Rofiqah ${ }^{1}$, Widayanti $^{1}$ \\ Program Studi Pendidikan Fisika STKIP Nurul Huda Sukaraja \\ *Coressponding author: destiprastikawati@gmail.com
}

Article History:

Received: juni 23, 2020

Revised: juli 10, 2020

Accepted: oktober 17, 2020

Published: desember 2, 2020

Keywords: STAD

Learning Model, Kokami

Media, Conventional

Model, Cognitive

Learning Outcomes

\begin{abstract}
The purpose of this study was to determine the effect and significance of the STAD learning model with mysterious card box media (kokami) on the physics learning outcomes of class VIII students on work and simple plane at SMP Negeri 1 Belitang Madang Raya in the 2020/2021 academic year. This research used quantitative research. The population in this study were all students of class VIII at SMP Negeri 1 Belitang Madang Raya, and the sample was selected by purposive sampling technique. In the experimental class, learning used the STAD learning model with kokami media, while in the control class, the learning used conventional models (lectures and questions and answers). Data collection techniques to determine the cognitive learning outcomes of students using a multiple-choice test with two tier question type, and hypothesis testing using the t-test. Based on the pretest and posttest results, the experimental class average score was higher than the control class average score. The pretest average score for the experimental class was 38, and the average score for the control class was 37. While the posttest average score for the experimental class was 75, and the control class was 63 . The average results of the experimental class and control class were different, so that there is a significant influence between students whose learning uses the STAD learning model through kokami media with students whose learning used conventional model. It can be seen from the tcount which is greater than the ttable value, namely 14.4> 1.67, which means that $\mathrm{HO}$ is rejected and Ha is accepted.
\end{abstract}

\begin{abstract}
Abstrak: Tujuan penelitian ini untuk mengetahui apakah terdapat pengaruh yang signifikan terhadap hasil belajar fisika peserta didik kelas VIII yang pembelajarannya menggunakan model pembelajaran STAD melalui media kotak kartu misterius (kokami) pada materi usaha dan pesawat sederhana di SMP Negeri 1 Belitang Madang Raya tahun pembelajaran 2020/2021. Penelitian ini menggunakan jenis penelitian kuantitatif. Populasi dalam penelitian ini seluruh peserta didik kelas VIII di SMP Negeri 1 Belitang Madang Raya. Pengambilan sampel dalam penelitian ini dengan teknik purposive sampling. Pada kelas eksperimen pembelajarannya menggunakan model pembelajaran STAD melalui media kokami, sedangkan pada kelas kontrol pembelajarannya menggunakan model konvensional (ceramah dan tanya jawab). Teknik pengumpulan data untuk mengetahui hasil belajar kognitif peserta didik menggunakan tes pilihan ganda dengan tipe soal two tier, dan pengujian hipotesisnya menggunakan uji-t. Berdasarkan hasil belajar kognitif setelah diadakan pretest dan posttest, nilai ratarata kelas eksperimen lebih tinggi daripada nilai rata-rata kelas kontrol. Nilai ratarata pretest kelas eksperimen sebesar 38 dan nilai rata-rata kelas kontrol sebesar 37. Sedangkan nilai rata-rata posttest kelas eksperimen sebesar 75 dan kelas kontrol sebesar 63. Hasil rata-rata kelas eksperimen dan kelas kontrol terdapat perbedaan, sehingga terdapat pengaruh yang signifikan antara peserta didik yang pembelajarannya menggunakan model pembelajaran STAD melalui media kokami dengan peserta didik yang pembelajarannya menggunakan model konvensional. Hal itu dapat dilihat dari thitung yang lebih besar daripada nilai ttabel yaitu 14,4 > 1,67 yang berarti bahwa H0 ditolak dan Ha diterima.
\end{abstract}




\section{PENDAHULUAN}

Pendidikan pada dasarnya dapat diwujudkan melalui pembelajaran yang mengaktifkan peserta didik agar memiliki kecerdasan, sikap, serta keterampilan (Alwi, F. Siska, 2015). Selain itu, pendidikan juga mencakup beberapa bidang, diantaranya bidang Ilmu Pengetahuan Alam (IPA). IPA mencakup fisika, biologi dan kimia dalam suatu mata pelajaran yang terpadu. IPA pada hakikatnya meliputi empat unsur utama yaitu: sikap, proses, produk dan aplikasi dalam kehidupan sehari-hari. Jadi dalam pembelajaran IPA harus muncul empat unsur utama tersebut agar tujuan pembelajaran dapat tercapai, salah satunya melalui pembelajaran fisika (Alwi, F. Siska, 2015).

Fisika sebagai salah satu ilmu yang wajib dipelajari di era perkembangan teknologi yang semakin pesat ini. Sebagian besar peserta didik kurang berminat terhadap pelajaran ini dan mengalami kesulitan. Alasannya beragam, mulai dari banyaknya rumus yang membutuhkan perhitungan yang tidak mudah, hingga pada proses pembelajaran yang berlangsung menjenuhkan/ membosankan.

Minat belajar dan kesulitan belajar tersebut pada akhirnya menyebabkan hasil akhir belajar fisika peserta didik rendah. Pada hasil wawancara peneliti dengan Ibu Suhartini, S.Pd. di SMP Negeri 1 Belitang Madang Raya dikatakan bahwa peserta didik merasa ketakutan terlebih dahulu ketika mendapatkan masalah tentang rumus dan hitung-menghitung. Kesulitan belajar ini terjadi karena pada saat pembelajaran, guru masih sering menggunakan model pembelajaran konvensional sehingga peserta didik tidak diberikan kesempatan untuk bertanya ataupun menanggapi penjelasan dari guru dan peserta didik mudah bosan dalam mengikuti pembelajaran (Prastikawati, 2020)

Menanggapi masalah tersebut kepala sekolah mengharapkan adanya inovasi atau pembaruan perlakuan guru terhadap proses pembelajaran. Pembelajaran yang banyak digunakan saat ini melalui model pembelajaran kooperatif. Pada model pembelajaran kooperatif, siswa diberi kesempatan untuk bekerja sama dalam mengerjakan tugas atau LKPD (Lie, 2014).

Model pembelajaran kooperatif yang paling banyak diaplikasikan di dalam kelas yaitu STAD (Slavin, 2015). Pada model pembelajaran STAD, siswa ditugaskan ke tim pembelajaran empat atau lima anggota. Tim tersebut terdiri dari siswa berprestasi tinggi, sedang, dan rendah, dan siswa laki-laki dan perempuan dari latar belakang ras atau etnis yang berbeda (Balfakih, 2013).

Model pembelajaran STAD juga sesuai untuk dipadukan dengan media pembelajaran. Gabungan antara media dan permainan dapat diterapkan melalui media kokami (Paisah, Neneng, 2013). Media kokami juga cocok dipadukan dalam langkah model pembelajaran STAD.

Media kokami terdiri dari sebuah kotak dan kartu misterius, dikatakan misterius sebab kartu dimasukkan ke dalam amplop yang kemudian amplop akan diletakkan di dalam suatu kotak sehingga isi dari kartu tidak diketahui. Isi dari kartu misterius dapat berupa materi, 
pertanyaan, gambar, perintah maupun suatu petunjuk, bonus, atau sanksi. Penggunaan media pada saat proses pembelajaran bertujuan untuk memotivasi belajar peserta didik, serta membuat suasana pembelajaran jadi menyenangkan (Arsyad, 2016).

Pada penelitian sebelumnya penerapan model pembelajaran STAD berbantuan media pembelajaran puzzle sangat efektif digunakan dan berpengaruh terhadap nilai belajar (Nurfarida, 2018). Pada penelitian Paisah, Neneng, (2013) menunjukkan penggunaan media kokami saat pembelajaran mampu meningkatkan kemampuan berpikir kritis.

Beda peneliti pada dua penelitian sebelumnya, peneliti ingin mengetahui pengaruh model pembelajaran STAD melalui media kotak kartu misterius (kokami) terhadap hasil belajar serta media yang digunakan bukan media puzzle.

\section{METODE}

Penelitian ini dilakukan di SMP Negeri 1 Belitang Madang Raya pada bulan September 2020. Pengambilan sampel dengan teknik purposive sampling. Kelas VIII.4 sebagai kelas kontrol, sedangkan kelas VIII.5 sebagai kelas eksperimen dengan pretest-posttest control group design, dalam desain ini kedua kelas diberi pretest sebelum proses pembelajaran (Sugiyono, 2015), seperti tabel 1.

Tabel 1. Desain Penelitian

\begin{tabular}{|c|c|c|c|}
\hline Subyek & Pre-Test & Perlakuan & Post-Test \\
\hline $\mathrm{E}$ & $\mathrm{O}_{1}$ & $\mathrm{X}_{\text {Eksperimen }}$ & $\mathrm{O}_{2}$ \\
\hline $\mathrm{K}$ & $\mathrm{O}_{1}$ & $\mathrm{X}_{\text {Kontrol }}$ & $\mathrm{O}_{2}$ \\
\hline
\end{tabular}

Keterangan:

$\mathrm{X}_{\text {eksperimen }}=$ Perlakuan kelas eksperimen (STAD melalui media kokami).

$\mathrm{X}_{\text {kontrol }}=$ Perlakuan kelas kontrol (konvensional).

$\mathrm{O}_{1}=$ Pretest diberikan kepada kedua kelompok sebelum diberikan perlakuan.

$\mathrm{O}_{2}=$ Posttest diberikan kepada kedua kelompok setelah diberikan perlakuan.

Adapun data diperoleh dari hasil kuesioner pra penelitian dan instrumen butir soal berupa pretest-posttest dalam aspek kognitif. Kuesioner pra penelitian diberikan pada saat observasi awal untuk mengetahui kebutuhan dan permasalahan pembelajaran pada peserta didik. Tes yang diberikan berupa tes tertulis (pretest dan posttest) dengan tipe soal two tier. Analisis data didapatkan dari perolehan hasil menghitung mean, standar deviasi, dan tingkat kesulitan pada soal. Kemudian, dilakukan pengujian hipotesis untuk mengetahui ada pengaruh atau tidak.

\section{HASIL DAN PEMBAHASAN}

Hasil penelitian aspek kognitif diperoleh dari hasil pretest -posttest. Hasil pretest-posttest kedua kelas seperti pada tabel 2.

Tabel 2. Hasil Pretest-Posttest

\begin{tabular}{|c|c|c|c|c|}
\hline \multirow{2}{*}{ Data } & \multicolumn{2}{|c|}{ Eksperimen } & \multicolumn{2}{c|}{ Kontrol } \\
\cline { 2 - 5 } & Pre & Post & Pre & Post \\
\hline $\begin{array}{c}\text { Skor } \\
\text { Terendah }\end{array}$ & 15 & 50 & 15 & 40 \\
\hline $\begin{array}{c}\text { Skor } \\
\text { Tertinggi }\end{array}$ & 60 & 95 & 55 & 85 \\
\hline $\begin{array}{c}\text { Mean } \\
\text { (Rata-Rata) }\end{array}$ & 38 & 75 & 37 & 63 \\
\hline $\begin{array}{c}\text { Standar } \\
\text { Deviasi }\end{array}$ & 9,13 & 11 & 8,42 & 10,49 \\
\hline
\end{tabular}


Setelah dianalisis berdasarkan hasil pretest, diperoleh persentase hasil pretest seperti pada tabel 3.

Tabel 3. Persentase Hasil Pretest

\begin{tabular}{|l|c|c|c|c|}
\hline \multirow{2}{*}{ Kategori } & \multicolumn{2}{|c|}{ Kelas Eksperimen } & \multicolumn{2}{c|}{ Kelas Kontrol } \\
\cline { 2 - 5 } & $\begin{array}{c}\text { Sumlah } \\
\text { Siswa }\end{array}$ & $\begin{array}{c}\text { Persen- } \\
\text { tase }\end{array}$ & $\begin{array}{c}\text { Jumlah } \\
\text { Siswa }\end{array}$ & $\begin{array}{c}\text { Persen- } \\
\text { tase }\end{array}$ \\
\hline Tinggi & 7 & $23 \%$ & 1 & $3 \%$ \\
\hline Sedang & 20 & $64 \%$ & 25 & $81 \%$ \\
\hline Rendah & 4 & $13 \%$ & 5 & $16 \%$ \\
\hline
\end{tabular}

Sedangkan berdasarkan hasil perhitungan dari data posttest, diperoleh persentase hasil posttest seperti pada tabel 4.

Tabel 4. Persentase Hasil Posttest

\begin{tabular}{|c|c|c|c|c|}
\hline \multirow[b]{2}{*}{$\begin{array}{c}\text { Kate- } \\
\text { gori }\end{array}$} & \multicolumn{2}{|c|}{ Kelas Eksperimen } & \multicolumn{2}{|c|}{ Kelas Kontrol } \\
\hline & $\begin{array}{l}\text { Jumlah } \\
\text { Siswa }\end{array}$ & $\begin{array}{c}\text { Persentase } \\
(\%)\end{array}$ & $\begin{array}{l}\text { Jumlah } \\
\text { Siswa }\end{array}$ & $\begin{array}{c}\text { Persentase } \\
(\%)\end{array}$ \\
\hline Tinggi & 10 & $32 \%$ & 1 & $3 \%$ \\
\hline Sedang & 20 & $62 \%$ & 22 & $71 \%$ \\
\hline Rendah & 2 & $6 \%$ & 8 & $26 \%$ \\
\hline
\end{tabular}

Selanjutnya dilakukan uji prasyarat yaitu uji normalitas dan uji homogenitas. Hasil pengujian normalitas pretest dan posttest kedua sampel penelitian seperti pada tabel 5 .

Tabel 5. Hasil Uji Normalitas Data Pretest dan Posttest

\begin{tabular}{|c|c|c|c|c|}
\hline \multirow{2}{*}{$\begin{array}{c}\text { Statis- } \\
\text { tik }\end{array}$} & \multicolumn{2}{|c|}{ Eksperimen } & \multicolumn{2}{c|}{ Kontrol } \\
\cline { 2 - 5 } & Pre & Post & Pre & Post \\
\hline$\chi_{\text {hitung }}^{2}$ & 2,05 & 8,28 & 3,41 & 6,52 \\
\hline$\chi_{\text {tabel }}^{2}$ & 11,07 & 11,07 & 11,07 & 11,07 \\
\hline Kesim- & $\chi^{2}$ hitung & $\chi^{2}$ hitung & $\chi^{2}$ hitung & $\chi^{2}$ hitung \\
pulan & $\chi^{2}$ tabel & $\chi^{2}$ tabel & $\chi_{\text {tabel }}^{2}$ & $\chi_{\text {tabel }}^{2}$ \\
& Data & Data & Data & Data \\
& Berdistri- & Berdistri- & Berdistri- & Berdistri- \\
& busi & busi & busi & busi \\
& Normal & Normal & Normal & Normal \\
\hline
\end{tabular}

Setelah kedua sampel kelompok dinyatakan berdistribusi normal, selanjutnya dilakukan pengujian homogenitas. Hasil uji homogenitas pretest dan posttest kedua kelompok sampel penelitian seperti pada tabel 6 .
Tabel 6. Hasil Uji Homogenitas

\begin{tabular}{|c|c|c|c|c|}
\hline Statistik & \multicolumn{2}{|c|}{ Pretest } & \multicolumn{2}{c|}{ Posttest } \\
\cline { 2 - 5 } & $\begin{array}{c}\text { Eksperi- } \\
\text { men }\end{array}$ & Kontrol & $\begin{array}{c}\text { Eksperi- } \\
\text { men }\end{array}$ & Kontrol \\
\hline $\mathrm{S}^{2}$ & 9,13 & 8,42 & 11 & 10,49 \\
\hline $\mathrm{F}_{\text {hitung }}$ & \multicolumn{2}{|c|}{1,08} & \multicolumn{2}{|c|}{1,04} \\
\hline $\mathrm{F}_{\text {tabel }}$ & \multicolumn{2}{|c|}{1,84} & \multicolumn{2}{|c|}{1,84} \\
\hline Kesimpulan & \multicolumn{2}{|c|}{ Homogen } & \multicolumn{2}{|c|}{ Homogen } \\
\hline
\end{tabular}

Berdasarkan tabel 6, untuk data pretest didapat $\mathrm{F}_{\text {hitung }}=1,08$ dan data posttest didapat $\mathrm{F}_{\text {hitung }}=1,04$, sedangkan $\mathrm{F}_{\text {tabel }}=1,84$. Dari kedua data tersebut didapatkan $F_{\text {hitung }}<\mathrm{F}_{\text {tabel }}$ yang artinya data tersebut homogen.

Pengujian data hasil belajar kedua kelompok dilanjutkan pada uji hipotesis menggunakan uji-t. Berdasarkan hasil perhitungan, diperoleh thitung untuk pretest sebesar 1,33 dan thitung untuk posttest sebesar 14,4 dengan nilai $t_{\text {tabel }}=1,67$. Hasil pengujian hipotesis seperti tabel 7.

Tabel 7. Hasil Pengujian Hipotesis

\begin{tabular}{|c|c|c|c|c|}
\hline \multirow{2}{*}{ Statistik } & \multicolumn{2}{|c|}{ Pre } & \multicolumn{2}{c|}{ Post } \\
\cline { 2 - 5 } & $\begin{array}{c}\text { Eksperi- } \\
\text { men }\end{array}$ & Kontrol & $\begin{array}{c}\text { Eksperi- } \\
\text { men }\end{array}$ & Kontrol \\
\hline $\mathrm{N}$ & 31 & 31 & 31 & 31 \\
\hline $\overrightarrow{\boldsymbol{x}}$ & 38 & 37 & 75 & 63 \\
\hline $\mathrm{SD}$ & 9,13 & 8,42 & 11 & 10,49 \\
\hline $\mathrm{t}_{\text {hitung }}$ & \multicolumn{2}{|c|}{1,33} & \multicolumn{2}{c|}{14,4} \\
\hline $\mathrm{t}_{\text {tabel }}$ & \multicolumn{2}{|c|}{1,67} & \multicolumn{2}{c|}{ Terdapat pengaruh } \\
\hline $\begin{array}{c}\text { Kesimpu } \\
\text {-lan }\end{array}$ & \multicolumn{2}{|c|}{$\begin{array}{c}\text { Tidak terdapat } \\
\text { pengaruh }\end{array}$} \\
\hline
\end{tabular}

Pada nilai pretest tampak bahwa $\mathrm{t}_{\text {hitung }}<\mathrm{t}_{\text {tabel }}$ yaitu $1,33<1,67$ sehingga $\mathrm{H}_{0}$ diterima dan Ha ditolak. Dengan demikian kedua kelas memiliki kemampuan yang homogen dan layak dijadikan sampel penelitian. Berbeda dengan hasil perolehan pretest, tampak bahwa kedua kelas setelah diberikan perlakuan yang berbeda didapat $t_{\text {hitung }}>\mathrm{t}_{\text {tabel }}$ yaitu 14,4> 1,67 sehingga $\mathrm{H}_{0}$ ditolak dan Ha diterima. Dengan diterimanya $\mathrm{H}_{\mathrm{a}}$ pada pengujian hipotesis tersebut, dapat disimpulkan 
bahwa penelitian ini dapat menguji kebenaran hipotesis. Sehingga dapat digambarkan seperti gambar 1.

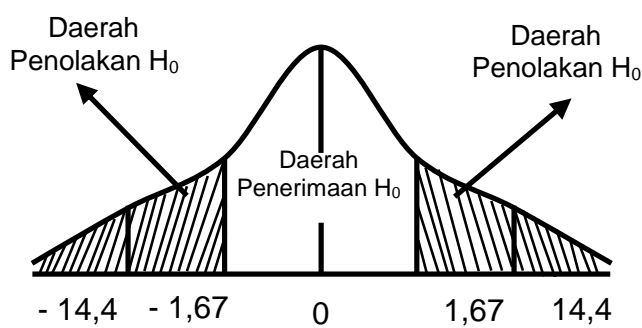

Gambar 1. Kurva Daerah Penerimaan dan Penolakan $\mathrm{H}_{0}$

Berdasarkan hasil uji prasyarat analisis, diketahui bahwa hasil pretestposttest terdistribusi normal. Dengan perolehan masing-masing $\chi_{\text {hitung }}^{2}<\chi_{\text {tabel. }}^{2}$ Selain itu, hasil pretest-posttest menunjukkan data homogen. Pada pengujian hipotesis melalui uji- $t$ dengan taraf siginifikansi 5\%, memperlihatkan hasil pretest kedua kelas tidak ada perbedaan. Karena $t_{\text {hitung }}<t_{\text {tabel }}$ yaitu 1,33 $<1,67$. Pada hasil posttest memperlihatkan bahwa peserta didik yang diberi perlakuan dengan model pembelajaran STAD melalui media kokami pada saat proses pembelajaran, menunjukkan hasil posttest yang lebih tinggi $\left(t_{\text {hitung }}>t_{\text {tabel }}\right.$ yaitu 14,4 $>$ 1,67). Selain itu, perolehan nilai thitung $>$ $t_{\text {tabel }}$ mengindikasikan adanya pengaruh yang cukup signifikan antara kedua kelas. Pengaruh tersebut dikarenakan adanya perbedaan perlakuan dalam proses pembelajaran masing-masing kelas, seperti tabel 8.
Tabel 8. Perbedaan perlakuan dalam Proses Pembelajaran Pada Kelas Eksperimen dan Kelas Kontrol

\begin{tabular}{|c|c|}
\hline $\begin{array}{c}\text { Model STAD melalui } \\
\text { media kokami }\end{array}$ & Model Konvensional \\
\hline 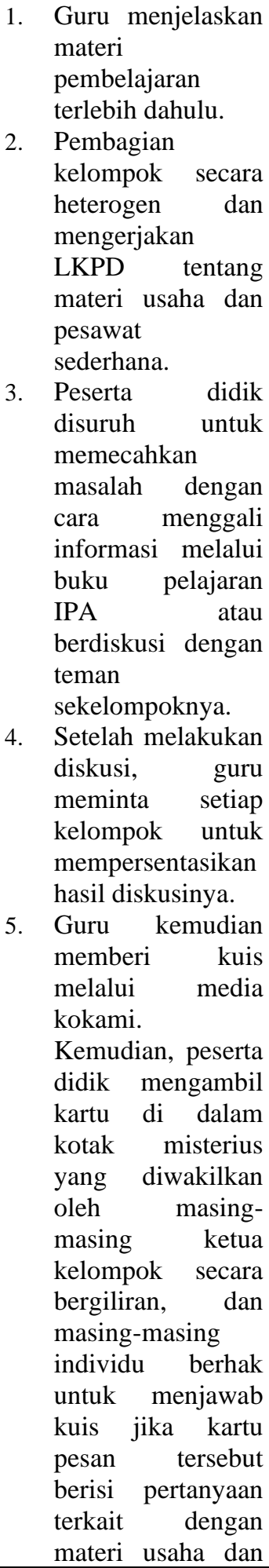 & 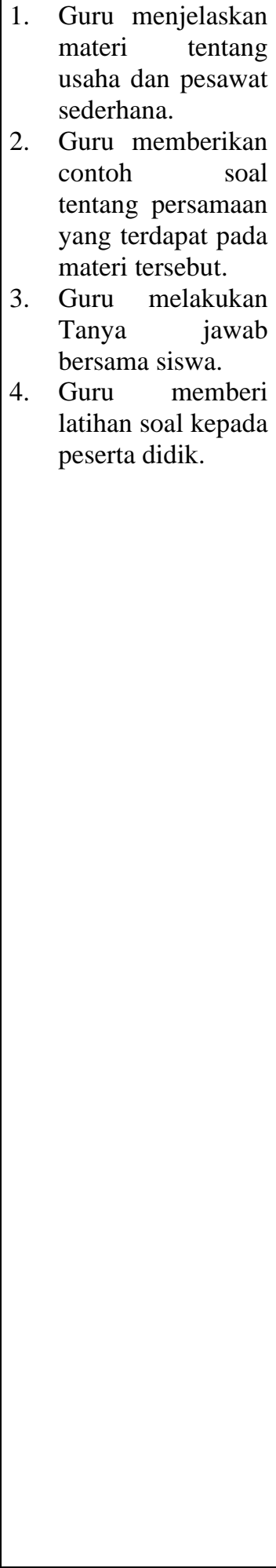 \\
\hline
\end{tabular}




\begin{tabular}{|l|l|}
\hline $\begin{array}{l}\text { Model STAD melalui } \\
\text { media kokami }\end{array}$ & Model Konvensional \\
\hline pesawat & \\
sederhana. \\
6. \\
Jika salah satu \\
peserta didik dari \\
salah satu \\
kelompok tidak \\
dapat menjawab \\
pertanyaan yang \\
terdapat di dalam \\
kartu pesan, maka \\
guru memberi tahu \\
kepada kelompok \\
lain untuk cepat \\
mengangkat \\
tangan dan berhak \\
untuk \\
menyelesaikan \\
pertanyaan terkait \\
dengan materi \\
usaha dan pesawat \\
sederhana. \\
Peserta didik \\
mendapatkan skor \\
jika berhasil \\
menjawab kuis \\
atau pertanyaan. \\
\hline
\end{tabular}

Menurut Alwi, F. Siska, (2015) pembelajaran melalui media kokami dapat membuat peserta didik bersemangat, percaya diri dan tidak tegang saat pembelajaran berlangsung sehingga tampak keseriusan peserta didik mengikuti pembelajaran dan terjadi interaksi aktif antara peserta didik dengan guru. Sedangkan menurut Paisah, Neneng, (2013) bahwa penggunaan kokami dapat meningkatkan kemampuan berfikir kritis.

Sedangkan menurut Suryadi, (2013) prestasi belajar peserta didik dengan Pembelajaran Berbasis Masalah (PBM) berbantuan media kokami lebih tinggi daripada pembelajaran yang tidak menggunakan media kokami. Sedangkan menurut penelitian Nurfarida, (2018) menunjukkan hasil positif dari penggunaan STAD berbantuan media puzzle terhadap hasil belajar siswa.

Penerapan STAD melalui kokami menuntut siswa untuk berperan aktif, berfikir secara kritis dalam mengerjakan kuis pada media kokami atau menjawab pertanyaan soal pretest-posttest, dan menumbuhkan semangat untuk lebih percaya diri dalam mengemukakan pendapatnya. Media kokami memiliki beberapa komponen yaitu kotak misterius, kartu pesan, dan amplop kartu pesan. Kartu pesan dari media kokami berisi perintah, petunjuk, materi, soal, bonus, dan juga sanksi. Media kokami yang dibuat oleh peneliti seperti pada gambar 2 .

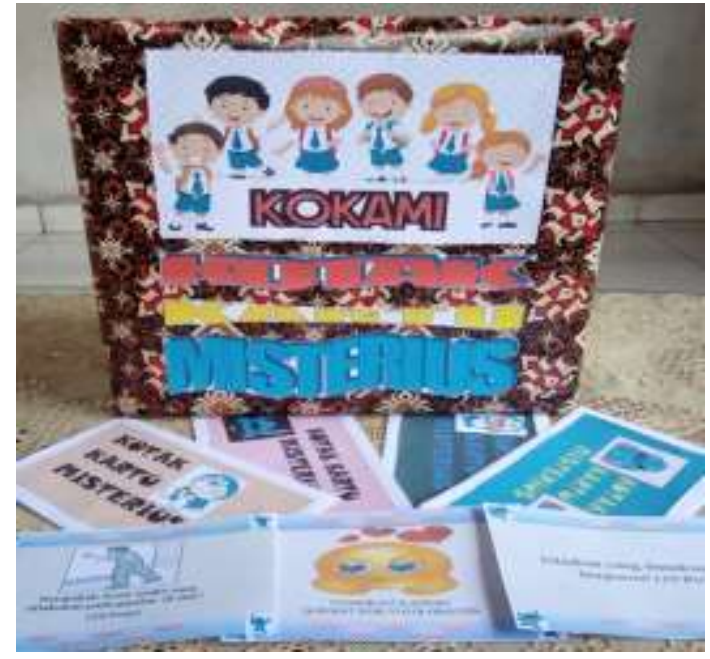

Gambar 2. Media kokami.

Melalui soal nomor 19 peserta didik mampu berpikir kritis dalam menjawab pertanyaan. Karena pada kelas eksperimen peserta didik mampu memahami masalah, menganalisis masalah, mengidentifikasi informasi yang relevan dengan masalah, merencanakan solusi, dan menarik kesimpulan. Soal dan jawaban hasil pretest-posttest seperti pada tabel 9. 
Tabel 9. Soal beserta Jawaban Pretest dan Posttest Peserta Didik pada Soal Nomor 19.

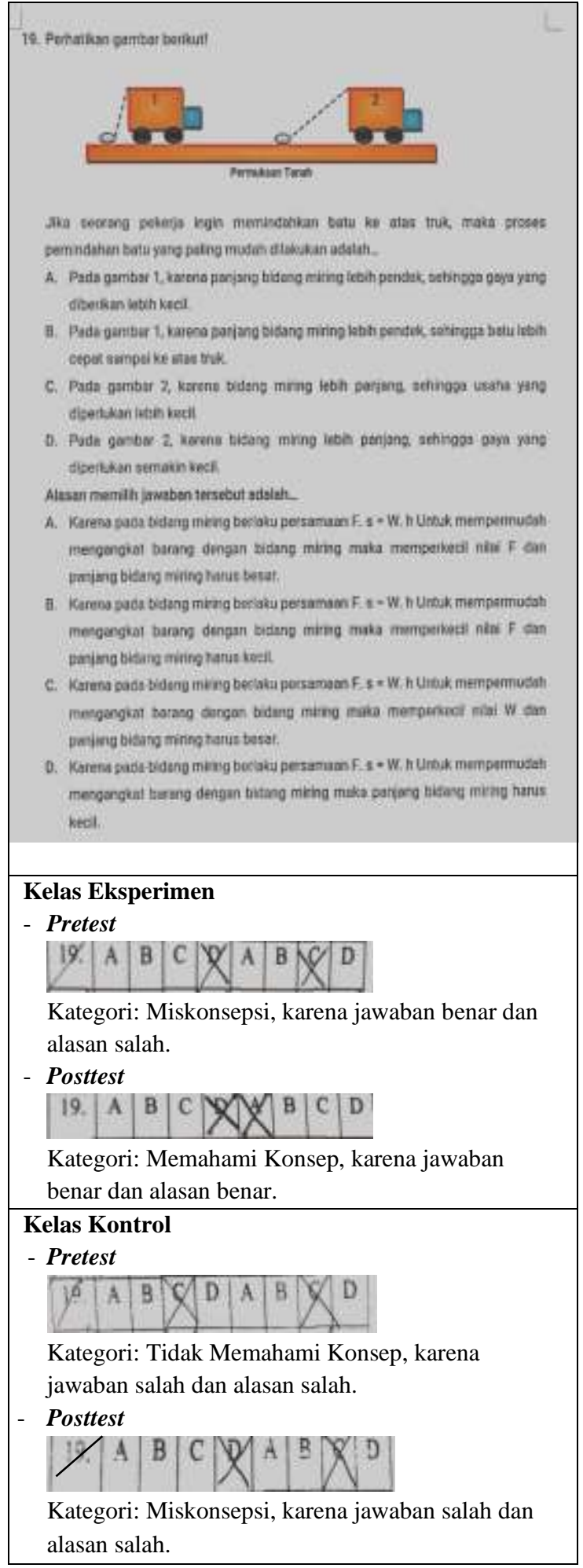

Sedangkan pembelajaran dengan menggunakan model konvensional, peserta didik yang memiliki kemampuan tinggi, lebih aktif dalam menyampaikan pendapat dan peserta didik dengan kemampuan rendah hanya diam, mendengarkan, dan mencatat hasil penjelasan yang diberikan oleh guru. Akibatnya, kelas hanya didominasi oleh beberapa peserta didik saja.

Penerapan STAD melalui kokami lebih efektif dan sangat berpengaruh terhadap nilai belajar fisika peserta didik. Pernyataan tersebut didukung oleh Balfakih, (2013) : "The findings have indicate that STAD is a more effective teaching method than the traditionalteaching method in teaching tenth grade chemistry classes in the UAE. The students' achievement scores of all students in experimental groups increased compared to their counterpart in control groups". yang artinya temuan (penelitian) menunjukkan bahwa model pembelajaran STAD lebih efektif daripada metode pembelajaran tradisional dalam mengajar kimia kelas sepuluh di UEA. Skor prestasi siswa dari semua siswa dalam kelompok eksperimen meningkat dibandingkan dengan rekan mereka dalam kelompok kontrol.

Namun, pada saat melakukan penelitian terdapat kendala yang dialami peneliti ketika menggunakan media kokami yaitu sulitnya mengontrol waktu dan mengontrol semua kegiatan peserta didik walaupun waktu dan kegiatan telah dibatasi pada langkah-langkah permainan kokami. Untuk mengatasi hal tersebut, pada saat kegiatan pembelajaran usahakanlah mengawasi peserta didik secara ketat, dan dapat menggunakan alarm yang menandakan waktu pengerjaan kuis atau soal telah habis sehingga waktu penyelesaian permainan 
kokami dapat terlaksana dengan baik dan tepat.

\section{SIMPULAN DAN SARAN}

Simpulan pada hasil penelitian diantaranya bahwa hasil belajar kognitif peserta didik yang diberi perlakuan dengan model STAD melalui media kokami memiliki rata-rata lebih besar (rata-rata pretest 38 dan rata-rata posttest 75). Sedangkan yang diberi perlakuan dengan model konvensional memiliki nilai rata-rata lebih kecil (rata-rata pretest 37 dan rata-rata posttest 63). Hasil thitung lebih besar daripada nilai tabel yaitu 14,4 > 1,67 diputuskan bahwa $\mathrm{H}_{0}$ ditolak dan $\mathrm{Ha}$ diterima. Sehingga terdapat pengaruh yang signifikan dari penerapan model STAD melalui media kotak kartu misterius terhadap hasil belajar fisika.

Hal-hal yang perlu disarankan oleh peneliti mengenai penggunaan media kokami dalam pembelajaran: sebaiknya media kokami dibuat dengan lebih mudah dan praktis, dapat memanfaatkan bahan yang sudah tak terpakai, dan dapat diaplikasikan dengan materi pembelajaran lainnya yang sesuai. Peneliti selanjutnya memahami langkah-langkah dan mengevaluasi waktu pembelajaran menggunakan media kokami sebelum pembelajaran dilaksanakan, sehingga dalam pelaksanaannya akan menjadi lebih efektif dan penyelesaian permainan kokami dapat terlaksana dengan tepat. Bagi peneliti lain agar lebih mengembangkan kreatifitasnya dalam memodifikasi media kokami dan pengelolaan kelas harus diperhatikan agar proses pembelajaran lebih tertib, sehingga mampu menumbuhkan peserta didik disiplin untuk belajar dan meningkatkan hasil belajar.

\section{DAFTAR PUSTAKA}

Alwi, F. Siska, D. (2015). Penerapan Metode Permainan Kokami Berdasarkan LKPD Saintifik dalam Model Quantum Learning terhadap Kompetensi IPA Peserta Didik Kelas VII SMPN 31 Padang. Jurnal Pillar Of Physics Education, 6, 59.

Arsyad, A. (2016). Media Pembelajaran. Jakarta: PT Raja Grafindo Persada.

Balfakih, M. A. N. (2013). The Effectiveness of Student Team Achievement Division (STAD) for Teaching High School Chemistry in the United Arab Emirates. International Journal of Science Education, 25(5), 608.

Lie, A. (2014). Cooperative Learning: Mempraktikkan Cooperative Learning di Ruang-Ruang Kelas. Jakarta: PT Grasindo.

Nurfarida, Y. (2018). Pengaruh Model Pembelajaran Student Team Achievement Division (STAD) Berbantuan Media Pembelajaran Puzzle terhadap Hasil Belajar Matematika Siswa Kelas VII di MTS Darul Hikmah Tawangsari. IAIN Tulungagung.

Paisah, Neneng, D. (2013). Penerapan Media Kotak dan Kartu Misterius (Kokami) untuk Peningkatan Keterampilan Berpikir Kritis pada Siswa Kelas VII SMP Negeri 25 Purworejo. Jurnal Radiasi, 3(1), 29.

Prastikawati, D. (2020). Wawancara Hasil Belajar di SMP Negeri 1 
Belitang Madang Raya. OKU Timur: Sumatera Selatan.

Slavin, E. R. (2015). Cooperative Learning: Theory, Research, and Practice. London: Allymand Bacon.

Sugiyono. (2015). Metode Penelitian Kuantitatif, Kualitatif, dan $R \& D$. Bandung: Alfabeta.

Suryadi. (2013). Pengaruh Pembelajaran Berbasis Masalah Berbantuan Media Kokami terhadap Prestasi Belajar Fisika Ditinjau dari Kemampuan Pemecaha Masalah. Jurnal Pendidikan Sains, 1(4). 